\title{
Périplos textuais e representações da educação literária no ensino básico
}

\author{
Dulce Melão
}

\begin{abstract}
Resumo
A Educação Literária tem sido recentemente alvo de atenção no Programa e Metas Curriculares de Português do Ensino Básico (2015), destacando-se o seu contributo para a formação de leitores, sobretudo ao conciliar práticas de leitura autónoma com itinerários que possam promover o ensino da compreensão do texto literário. Neste estudo refletimos sobre tais desafios, a partir de um conjunto de planificações realizadas no âmbito de um trabalho efetuado na unidade curricular de Iniciação à Leitura e à Escrita (1. ${ }^{\circ}$ Ciclo de Estudos em Educação Básica, 3. ${ }^{\circ}$ ano), centrado na exploração do domínio da Educação Literária em articulação com o ensino do desenvolvimento da compreensão na leitura. Utilizando como instrumentos 12 planificações elaboradas pelos estudantes, tivemos como objetivo investigar qual a relevância da Educação Literária em sala de aula para estes estudantes, através da análise das suas diferentes propostas de operacionalização dos objetivos incluídos em tal domínio, cruzando-o com o domínio da Leitura e Escrita. Inferimos que depreciavam alguns dos objetivos e respetivos descritores de desempenho no âmbito da Educação Literária, fazendo, por vezes, uma articulação débil com o domínio da Leitura e Escrita. Concluímos que é necessário que existam programas de formação que possibilitem aos futuros profissionais da Educação consolidar o gosto pela leitura, de modo a que tal possa vir a repercutir-se no seu futuro público.
\end{abstract}

Palavras-chave:

educação literária; leitura; ensino do Português; profissionais da educação. 


\section{Textual Journeys and Conceptions of Literary Education in Basic Education}

Abstract: Literary Education has recently been the focus of the Program and Curricular Goals of Portuguese in Basic Education (2015) and its contribution to the training of readers has been highlighted, especially regarding the compromise between autonomous reading practices and itineraries that encourage teaching literary text comprehension. In this study, we reflect upon these challenges, based on a set of lesson plans completed by means of a work developed in the curricular unit of Initiation to Reading and Writing (1st degree in Basic Education, 3rd year), centered on the exploration of the domain of Literary Education in articulation with teaching of the development of reading comprehension. Instruments used to gather data were 12 lesson plans developed by students, with the aim to investigate the relevance they attached to Literary Education in the classroom, through the analysis of their different proposals to operationalize the targets included in such domain, crossing it with the domain of Reading and Writing. We infer that they depreciate some of the objectives and respective targets within the scope of Literary Education, sometimes making a weak articulation with the domain of Reading and Writing. We conclude that there is a need for training programs that will enable future education professionals to consolidate their motivation for reading, for the repercussions on their future public.

Keywords: literary education; reading; teaching of Portuguese; educational professionals.

\section{Voyages Textuels et Représentations de l'Éducation Littéraire dans Éducation Basique}

Résumé: L'éducation littéraire a été récemment objet d'attention dans le Programme et Objectifs Curriculaires du Portugais pour l'Enseignement Basique, mettant en évidence sa contribution à la formation de lecteurs, surtout en ce qui concerne concilier des pratiques de lecture autonome avec des itinéraires qui puissent encourager l'enseignement de la compréhension du texte littéraire. Dans cette étude, nous réfléchissons sur ces défis à partir d'un ensemble de plans de leçons élaborés à propos d'un travail effectué dans le cours d'Introduction à la Lecture et à l'Écriture (Licence en Éducation Basique, 3ème année) sur l'exploration du domaine de l'Éducation Littéraire en rapport avec l'enseignement du développement de la compréhension de la lecture. Les instruments utilisés ont été 12 plans de leçons élaborés par les étudiants, ayant comme objectif d'investiguer l'importance attribuée par les étudiants à l'Éducation Littéraire dans la classe. On a pu déduire que les étudiants ont décrit certains objectifs en ce qui concerne l'Éducation Littéraire, établissant, parfois, une connexion faible avec de domaine de la Lecture et le l'Écriture. Nous concluons par la nécessité de la création des programmes de formation qui permettent aux futurs professionnels de l'Éducation de consolider des habitudes de lecture, pour que cela puisse se réfléchir dans leur futur public.

Mots-clés: éducation littéraire; lecture; enseignement du Portugais; professionnels de l'éducation.

\section{Periplos Textuales y Representaciones de la Educación Literaria en la Educación Básica}

Resumen: La educación literaria ha recibido recientemente atención en el Programa y Metas Curriculares de Portugués de la Educación Básica (2015), destacando-se su contribución a la formación de lectores, particularmente con respecto al reconciliar de prácticas de lectura autónoma con itinerarios que pueden promover la enseñanza de la comprensión del texto literario. En este estudio se reflexiona sobre estos desafíos a partir de un conjunto de planes de aula realizados en un trabajo de la unidad curricular de Introducción a la Lectura y Escritura (Grado en Educación Básica, 3er año) centrado en la exploración de la educación literaria en articulación con la enseñanza del desarrollo de la comprensión lectora. Utilizando como instrumentos 12 planes de aula desarrollados por los estudiantes, nuestro objetivo fue investigar la relevancia de Educación Literaria para estos estudiantes en las clases, a través del análisis de sus diferentes propuestas para poner en práctica los objetivos allí incluidos, cruzándolos con el campo de la Lectura y la Escritura. Deducimos que menospreciaran a algunas de las metas y los respectivos descriptores de desempeño de la educación literaria, haciendo, a veces, una conexión débil con la lectura y la escritura. Concluimos que es necesario que existan programas de entrenamiento que permitan a los futuros profesionales de la educación consolidar los hábitos de lectura, por lo que esto pueda llegar a ser reflejado en su futuro público.

Palavras clave: educación literaria; lectura; enseñanza del portugués; profesionales de educación. 


\section{Introdução}

Numa sociedade crescentemente apodada de digital, o caráter central da leitura, entendida na sua pluralidade, tem vindo a ser revisitado e repensado, de diversas formas, em contexto escolar, sendo reconhecida a importância que possui na/para a formação dos cidadãos (Azevedo \& Balça, 2016; Ceia, 2011).

O destaque atual dado à Educação Literária na escola, renovando práticas de leitura, acentua a relevância do acolhimento do texto literário na sala de aula (Bernardes \& Mateus, 2013; Nogueira, 2011), bem como em outros contextos que possibilitem a sua fruição. Nesse sentido, as representações da Educação Literária dos mediadores privilegiados de tal fruição - os futuros profissionais da Educação - merecem cuidado redobrado, pois a sua compreensão detalhada poderá favorecer dados relevantes que contribuam para uma reavaliação da sua formação e, por consequência, possam vir a repercutir-se nas suas práticas educativas.

No entendimento da relevância dos aspetos referidos, este artigo obedece à seguinte estrutura: i) breve enquadramento teórico, respeitante à educação literária e à formação de leitores e sua articulação com o itinerário de investigação pelo qual optamos; ii) explicitação dos objetivos do estudo e sua descrição; iii) apresentação dos resultados do estudo, contemplando a análise detalhada das suas componentes. Tecemos, ainda, algumas considerações «finais», procurando lançar luz sobre os caminhos trilhados, antecipando a possibilidade de novos desafios.

\section{A educação literária e a formação de leitores}

Atualmente, a articulação entre a formação de leitores e a Educação Literária ${ }^{1}$ tem vindo a ser alvo de particular atenção, em contexto escolar, por várias razões (enumeramos apenas algumas que, em nosso entender, assumem maior relevo). Em primeiro lugar, pelo reconhecimento da necessidade de lançar um olhar renovado sobre práticas de leitura crescentemente diversificadas, no nosso quotidiano (Mangen, 2016; Martos Nuñez \& Campos Fernández-Figares, 2013). Em segundo lugar, pela valorização da leitura na sociedade em geral, enquanto possível requisito de um exercício de cidadania responsável, entendido na sua multidimensionalidade (EACEA/Eurydice, 2012). Em terceiro lugar, pela reflexão redobrada em torno do repensar do papel do ensino da literatura em contexto de sala de aula (Bernardes \& Mateus, 2013; Ceia, 2011).

No que respeita ao $1 .^{\circ}$ e ao $2 .^{\circ}$ Ciclo do Ensino Básico, a Educação Literária tem ganho destaque, por exemplo: i) através do desenvolvimento do Plano Nacional de Leitura (PNL); ii) através da implementação (e respetiva operacionalização) do Programa e Metas Curriculares de Português (Buescu et al., 2015); iii) nos manuais de Português, em cumprimento das normas de avaliação e certificação em vigor. 
Investigação recente tem igualmente incidido na importância da Educação Literária em articulação com a leitura, no que respeita à formação de leitores, contemplando diferentes níveis de ensino (Azevedo \& Balça, 2016; Menezes \& Coelho, 2016).

Relativamente aos estudantes do ensino superior encarados na sua globalidade, estudos nacionais e internacionais que contemplam os seus perfis de leitor têm possibilitado alguma reflexão sobre as suas representações da leitura, focando, sobretudo, o modo como a motivação para a leitura e o desempenho em compreensão na leitura se podem refletir na sua formação (por exemplo, Oliveira, 2011; Parlette \& Howard, 2010).

Quanto aos estudantes futuros profissionais da Educação, têm sido destacados: i) a sua dificuldade em descrever o texto literário e a representação subjetiva que associam à literatura (Baleiro, 2011); ii) a desvalorização de práticas de leitura com fins recreativos (Fernandes \& Maia, 2013; Owusu-Acheaw \& Larson, 2014); iii) a importância que atribuem à leitura com fins académicos (Juchum, 2014; Melão, 2016); iv) o caráter «instrumental» que reconhecem à leitura (Granado, 2014; Yubero, Larrañaga \& Pires, 2014).

Face ao exposto, parece-nos ser relevante indagar quais os "lugares» da Educação Literária em contexto de sala de aula para os estudantes futuros profissionais da Educação, pelas suas possíveis repercussões em práticas educativas futuras. Nesse sentido, o itinerário pelo qual enveredámos diz respeito à análise de doze planificações realizadas por estudantes inscritos na unidade curricular de Iniciação à Leitura e à Escrita, integrada no $3 .^{\circ}$ ano do plano de estudos da Licenciatura em Educação Básica da Escola Superior de Educação de Viseu, no $1 .{ }^{\circ}$ semestre dos anos letivos de 2014-2015 (25 estudantes do sexo feminino e 2 estudantes do sexo masculino) e de 2015-2016 (27 estudantes do sexo feminino e 1 estudante do sexo masculino).

As planificações enquadram-se no âmbito de um trabalho em grupo proposto aos estudantes centrado na exploração do domínio da Educação Literária, em articulação com o desenvolvimento da compreensão na leitura (de acordo com os objetivos contemplados no domínio da Leitura e Escrita).

Consideramos que tais planificações possibilitam o desvelar da compreensão das suas representações da Educação Literária, no entendimento de que «As práticas educativas (...) são instrumentos veiculadores das representações construídas historicamente por uma dada sociedade. As representações são modelos pessoais de organização dos conhecimentos, valores e concepções sobre um objeto ligado à prática e à expressão social de cada indivíduo" (Bona \& Silva, 2009, p. 16).

Como sublinha Moscovici (1976), os indivíduos participam num processo permanente de produção/comunicação das suas representações com/a outros, no âmbito das interações sociais que plasmam o quotidiano, devendo ser valorizado o conhecimento do senso comum, pelas suas possíveis repercussões em práticas educativas que se entretecem em tal quotidiano. 


\section{Objetivos do estudo e sua descrição}

O objetivo principal do nosso estudo foi caracterizar as representações da Educação Literária dos estudantes futuros profissionais de Educação, investigando as suas possíveis repercussões em práticas educativas futuras. Nesse sentido, foi solicitado aos estudantes que levassem a cabo, em grupo, uma planificação de atividades a realizar em contexto de sala de aula (no âmbito do $1 .{ }^{\circ}$ ou do $2 .^{\circ}$ Ciclo do Ensino Básico), contemplando os domínios da Educação Literária e da Leitura e Escrita.

Através da realização do trabalho proposto aos estudantes, pretendia-se que estes:

- Aprofundassem a sua compreensão sobre o domínio da Educação Literária no $1 .{ }^{\circ}$ e 2. ${ }^{\circ}$ Ciclos do Ensino Básico;

- Compreendessem a importância da articulação entre o domínio da Educação Literária e o domínio da Leitura e Escrita, nos níveis de ensino contemplados.

O trabalho foi realizado em várias fases, de forma complementar, como passamos, seguidamente, a explicitar:

- Seleção do nível de ensino/ano de escolaridade para o qual pretendiam trabalhar;

- Seleção de uma obra/de um texto incluída(o) na «lista de obras e textos para Educação Literária»;

- Análise e discussão, em contexto de sala de aula, de documentos sobre estratégias didáticas de motivação para a leitura e de desenvolvimento da compreensão na leitura;

- Planificação de atividades para a abordagem do texto selecionado;

- Apresentação das atividades construídas pelos grupos, em contexto de sala de aula;

- Elaboração do trabalho escrito com a planificação das atividades propostas e sua respetiva fundamentação, no âmbito do seu trabalho autónomo.

Os grupos eram constituídos por 3 a 5 elementos, de acordo com a disponibilidade manifestada e com o número de estudantes das respetivas turmas, tendo sido facultado um período de 20 a 30 minutos para a apresentação do trabalho realizada em contexto de sala de aula.

\subsection{Apresentação dos resultados do estudo}

\subsubsection{Nível de ensino e ano de escolaridade}

Foi possível inferir que, no ano letivo 2014-2015, os estudantes preferiram planificar atividades para o $2 .^{\circ}$ ano do $1 .^{\circ}$ Ciclo de escolaridade (2 grupos) e para o $5 .^{\circ} \mathrm{e}$ $6 .^{\circ}$ ano do $2 .^{\circ}$ Ciclo de escolaridade (dois grupos para cada ano, perfazendo um total de 4 grupos). Apenas um grupo selecionou o $1 .^{\circ}$ ano do $1 .{ }^{\circ}$ Ciclo do Ensino Básico, 
talvez por associar maiores dificuldades à planificação de atividades no âmbito de tal ano de escolaridade.

No ano letivo 2015-2016, a escolha dos estudantes recaiu sobretudo no $1 .{ }^{\circ}$ Ciclo (3. ${ }^{\circ}$ e $4 .^{\circ}$ anos), o que poderá dever-se à sua preferência, em particular, por este nível de ensino.

\subsubsection{Seleção de obras/de textos}

$\mathrm{Na}$ Tabela 1 apresentamos as obras/os textos selecionadas(os) pelos grupos ${ }^{2}$ e seu respetivo ano de escolaridade:

Tabela 1 - Seleção de obras/textos - ano de escolaridade

\begin{tabular}{|c|c|c|}
\hline \multicolumn{3}{|c|}{ Ano letivo 2014-2015 } \\
\hline Grupos & Obras/Textos & $\begin{array}{l}\text { Ano de } \\
\text { escolaridade }\end{array}$ \\
\hline Grupo 1 & A girafa que comia estrelas (José Eduardo Agualusa) & 2. ${ }^{\circ}$ ano \\
\hline Grupo 2 & Ulisses (Maria Alberta Menéres) & $6 .^{\circ}$ ano \\
\hline Grupo 3 & Rosa, minha irmã Rosa (Alice Vieira) & $6 .^{\circ}$ ano \\
\hline Grupo 4 & O rapaz de bronze (Sophia de Mello Breyner Andresen) & $5 .^{\circ}$ ano \\
\hline Grupo 5 & O elefante cor-de-rosa (Luísa Dacosta) & 2. ${ }^{\circ}$ ano \\
\hline Grupo 6 & O coelhinho branco (António Torrado) & 1. ${ }^{\circ}$ ano \\
\hline Grupo 7 & A fada Oriana (Sophia de Mello Breyner Andresen) & $5 .^{\circ}$ ano \\
\hline \multicolumn{3}{|c|}{ Ano letivo 2015-2016 } \\
\hline Grupo 8 & O rato e a lua (em Trinta por uma linha; António Torrado) & 3..$^{\circ}$ ano \\
\hline Grupo 9 & A cor das vogais (Vergílio Alberto Vieira) & $3 .^{\circ}$ ano \\
\hline Grupo 10 & $\begin{array}{c}\text { A princesa e a ervilha (em Contos de Andersen; Hans Christian } \\
\text { Andersen) }\end{array}$ & $4 .^{\circ}$ ano \\
\hline Grupo 11 & Uma flor chamada Maria (Alves Redol) & $2 .^{\circ}$ ano \\
\hline Grupo 12 & A maior flor do mundo (José Saramago) & 4. ${ }^{\circ}$ ano \\
\hline
\end{tabular}


Da análise da Tabela 1 concluímos que os estudantes selecionaram, sobretudo, textos narrativos de autores Portugueses, podendo tal preferência estar relacionada: i) com o facto de, no que se refere ao nível de ensino escolhido, predominarem os autores Portugueses; ii) com a valorização acrescida que concedem aos autores Portugueses no âmbito da Educação Literária do seu futuro público.

Importa destacar que nenhum grupo escolheu o texto dramático, tendo o texto poético sido apenas preferido por um grupo (Grupo 9). Múltiplas razões poderão justificar tais escolhas, por exemplo: i) o gosto pessoal dos estudantes; ii) a possibilidade de considerarem a abordagem dos textos poéticos e dos textos dramáticos, em contexto de sala de aula, mais complexa do que a dos textos narrativos, preferindo estes últimos; iii) a possibilidade de, ao longo do seu percurso escolar, ter sido privilegiado o texto narrativo; iv) a existência de possíveis dificuldades, a nível individual, relativamente à compreensão na leitura dos tipos/géneros textuais referidos.

\subsubsection{Parâmetros contemplados nas planificações}

Apresentamos, seguidamente, os resultados da análise dos diferentes parâmetros contemplados nas planificações: i) domínios, objetivos e descritores de desempenho selecionados, de acordo com o nível de ensino e com o ano de escolaridade selecionados; ii) estratégias do leitor incluídas nas planificações, de acordo com as diferentes fases do ato de leitura. ${ }^{3}$

Todos os grupos optaram, cumulativamente, pelo domínio da Leitura e Escrita e pelo domínio da Educação Literária (ou, no caso de atividades planificadas para o $1 .^{\circ}$ e para o 2..$^{\circ}$ ano de escolaridade, pela Iniciação à Educação Literária). Os objetivos e descritores de desempenho ${ }^{4}$ selecionados pelos grupos relativamente ao domínio da Educação Literária (1. ${ }^{\circ}$ Ciclo do Ensino Básico) são apresentados na Tabela 2: 
Tabela 2 - Objetivos e descritores da Educação Literária - 1. ${ }^{\circ}$ Ciclo do Ensino Básico

\begin{tabular}{|c|c|c|c|}
\hline Domínio & $\begin{array}{c}\text { Ano de } \\
\text { escolaridade }\end{array}$ & Objetivos & Descritores de desempenho \\
\hline \multirow{8}{*}{$\begin{array}{l}\text { Iniciação à } \\
\text { Educação } \\
\text { Literária / } \\
\text { Educação } \\
\text { Literária }\end{array}$} & \multirow[t]{2}{*}{$1 .{ }^{\circ}$ ano } & $\begin{array}{l}\text { - Compreender } \\
\text { o essencial dos } \\
\text { textos escutados e } \\
\text { lidos (IEL1.17). }\end{array}$ & - Recontar uma história ouvida (IEL1.17.4). \\
\hline & & $\begin{array}{l}\text { - Ler para apreciar } \\
\text { textos literários } \\
\text { (IEL1.18). } \\
\end{array}$ & $\begin{array}{l}\text { - Ouvir ler e ler obras de literatura para } \\
\text { a infância e textos da tradição popular } \\
\text { (IEL1.18.1). }\end{array}$ \\
\hline & \multirow[t]{2}{*}{$2 .^{\circ}$ ano } & $\begin{array}{l}\text { - Compreender } \\
\text { o essencial dos } \\
\text { textos escutados e } \\
\text { lidos (IEL2.20). }\end{array}$ & $\begin{array}{c}\text { - Antecipar conteúdos com base no título e } \\
\text { nas ilustrações (IEL2.20.1); } \\
\text { - Interpretar as intenções e as emoções das } \\
\text { personagens de uma história (IEL2.20.3); } \\
\text { - Fazer inferências (de sentimento, atitude) } \\
\text { (IEL2.20.4); } \\
\text { - Recontar uma história ouvida e lida } \\
\text { (IEL2.20.5). }\end{array}$ \\
\hline & & $\begin{array}{l}\text { - Ler para apreciar } \\
\text { textos literários } \\
\quad \text { (IEL2.21). }\end{array}$ & $\begin{array}{l}\text { - Ouvir ler e ler obras de literatura para } \\
\text { a infância e textos da tradição popular } \\
\text { (IEL2.21.1.); } \\
\text { - Exprimir sentimentos e emoções provocados } \\
\text { pela leitura de textos (IEL2.21.2). }\end{array}$ \\
\hline & \multirow{2}{*}{$3 .^{\circ}$ ano } & $\begin{array}{l}\text { - Ler e ouvir ler } \\
\text { textos literários } \\
\quad(\text { EL3.21). }\end{array}$ & $\begin{array}{c}\text { - Ler e ouvir ler obras de literatura para a } \\
\text { infância (EL3.21.1.). } \\
\text { - Praticar a leitura silenciosa (EL3.21.2); } \\
\text { - Ler em voz alta, após preparação da leitura } \\
\text { (EL3.21.3). }\end{array}$ \\
\hline & & $\begin{array}{l}\text { - Compreender } \\
\text { o essencial dos } \\
\text { textos escutados e } \\
\text { lidos (EL3.22). }\end{array}$ & $\begin{array}{c}\text { - Confrontar as previsões feitas sobre o texto } \\
\text { com o assunto do mesmo (EL3.22.2); } \\
\text { - Responder, oralmente e por escrito, de } \\
\text { forma completa, a questões sobre os textos } \\
\text { (EL3.22.9). }\end{array}$ \\
\hline & \multirow{2}{*}{$4 .^{\circ}$ ano } & $\begin{array}{l}\text { Ler e ouvir ler } \\
\text { textos literários } \\
\text { (EL4.23). }\end{array}$ & $\begin{array}{c}\text { - Ler e ouvir ler obras de literatura para } \\
\text { a infância e textos da tradição popular } \\
\text { (EL4.23.1). } \\
\text { - Fazer a leitura expressiva de pequenos } \\
\text { textos, após preparação da mesma } \\
\text { (EL4.23.2). }\end{array}$ \\
\hline & & $\begin{array}{l}\text { - Compreender } \\
\text { o essencial dos } \\
\text { textos escutados e } \\
\text { lidos (EL4.24). }\end{array}$ & $\begin{array}{l}\text { - Recontar histórias lidas, distinguindo } \\
\text { introdução, desenvolvimento e conclusão } \\
\text { (EL4.24.6); } \\
\text { - Responder oralmente e por escrito, de } \\
\text { forma completa, a questões sobre os textos } \\
\text { (EL4.24.10). }\end{array}$ \\
\hline
\end{tabular}


Da análise da Tabela 2 inferimos que os estudantes, independentemente do ano de escolaridade ao qual dizia respeito a planificação das atividades, destacaram sobretudo os objetivos «Ler para apreciar textos literários» (IEL1.17; IEL1.18), «Ler e ouvir ler textos literários» (EL3.21; EL4.23) e «Compreender o essencial dos textos escutados e lidos» (IEL1.17; IEL2.20; EL3.22; EL4.24).

Os descritores de desempenho selecionados apontam, sobretudo para o destaque conferido: i) ao reconto da história lida; ii) às modalidades de leitura; iii) à resposta, oralmente e por escrito, a questões sobre os textos.

Relativamente ao $3 .^{\circ}$ e ao $4 .^{\circ}$ ano de escolaridade, importa ainda salientar a ausência, no âmbito do objetivo «Ler e ouvir ler textos literários», dos descritores de desempenho que dizem respeito à manifestação de sentimentos, ideias e pontos de vista suscitados pelas histórias ouvidas (EL3.23.2; EL4.25.2). Tal poderá indiciar: i) a sua desvalorização por parte dos estudantes, em associação com possíveis dificuldades na sua operacionalização; ii) o modo como os estudantes, individualmente, fruem o texto literário (por exemplo, no que se refere a vivências em contexto escolar e extraescolar que possam ter contribuído para a depreciação do mesmo).

Atribuímos também relevância à depreciação do estabelecimento de inferências (apenas referido uma vez, no âmbito do $2 .^{\circ}$ ano de escolaridade), ausente dos descritores de desempenho escolhidos para o $3 .^{\circ}$ e para o $4 .^{\circ}$ ano de escolaridade embora muito vincado no Programa e Metas Curriculares de Português (Buescu et al., 2015, p. 14 ; p. 17 ; p. 56; p. 61).

$\mathrm{Na}$ Tabela 3 apresentamos os objetivos e descritores de desempenho incluídos pelos grupos nas suas planificações no âmbito do domínio da Educação Literária (2. Ciclo do Ensino Básico):

Tabela 3 - Objetivos e descritores da Educação Literária - 2. ${ }^{\circ}$ Ciclo do Ensino Básico

\begin{tabular}{|c|c|c|c|}
\hline Domínio & $\begin{array}{c}\text { Ano de } \\
\text { escolaridade }\end{array}$ & Objetivos & Descritores de desempenho \\
\hline \multirow{2}{*}{$\begin{array}{l}\text { Educação } \\
\text { Literária }\end{array}$} & $5 .^{\circ}$ ano & $\begin{array}{c}\text { - Ler e } \\
\text { interpretar } \\
\text { textos literários } \\
\text { (EL5.20). }\end{array}$ & $\begin{array}{l}\text { - Reconhecer a estrutura e elementos } \\
\text { constitutivos do texto narrativo: personagens } \\
\text { (principal e secundária; narrador) (EL5.20.5); } \\
\text { - Responder, de forma completa, a questões } \\
\text { sobre os textos (EL5.20.10). }\end{array}$ \\
\hline & $6 .^{\circ}$ ano & $\begin{array}{c}\text { - Ler e } \\
\text { interpretar } \\
\text { textos literários } \\
\text { (EL6.18). }\end{array}$ & $\begin{array}{c}\text { - Relacionar partes do texto (modos narrativo e } \\
\text { lírico) com a sua estrutura global) (EL6.18.3). } \\
\text { - Responder, de forma completa, a questões } \\
\text { sobre os textos (EL6.18.11). }\end{array}$ \\
\hline
\end{tabular}


Da análise da Tabela 3 podemos inferir que os grupos que planificaram atividades para o $5 .^{\circ}$ e para o $6 .^{\circ}$ ano de escolaridade concederam idêntica relevância à leitura e à interpretação de textos literários. Depreendemos também que preferiram centrar o seu trabalho na estrutura do texto narrativo, sendo relevante a ausência dos objetivos «Tomar consciência do modo como os temas, as experiências e os valores são representados nos textos literários» (EL5.21; EL6.19) e "Ler e escrever para fruição estética» (EL5.22; EL6.20). Tal poderá ter ocorrido: i) por os estudantes terem dificuldade em associar as atividades desenvolvidas a tais objetivos; ii) por não Ihes atribuírem importância no que se refere à Educação Literária; iii) pelas suas práticas de leitura em contexto escolar e extraescolar não terem favorecido a valorização de tais aspetos.

Importa realçar que do objetivo «Ler e interpretar textos literários» (EL6.18) se encontra ausente o descritor de desempenho «Manifestar-se em relação a aspetos da linguagem que conferem a um texto qualidade literária (por exemplo, vocabulário, conotações, estrutura)» (LE6.18.8). A desvalorização da sua operacionalização poderá ter subjacentes dificuldades dos estudantes relativamente aos aspetos da linguagem que contempla, repercutindo-se nas suas práticas educativas futuras.

$\mathrm{Na}$ Tabela 4 apresentamos os resultados da análise das planificações dos grupos, no que se refere aos objetivos e aos descritores de desempenho incluídos nas planificações, no âmbito do domínio da Leitura e Escrita (1. Ciclo do Ensino Básico): 
Melão: Périplos textuais e representações da educação literária no ensino básico

Tabela 4 - Objetivos e descritores da Leitura e Escrita - 1. ${ }^{\circ}$ Ciclo do Ensino Básico

\begin{tabular}{|c|c|c|c|}
\hline Domínio & $\begin{array}{c}\text { Ano de } \\
\text { escolaridade }\end{array}$ & Objetivos & Descritores de desempenho \\
\hline \multirow{4}{*}{$\begin{array}{c}\text { Leitura e } \\
\text { Escrita }\end{array}$} & $1 .{ }^{\circ}$ ano & $\begin{array}{l}\text { - Ler textos diversos } \\
\text { (LE1.8); } \\
\text { - Relacionar o texto } \\
\text { com conhecimentos } \\
\text { anteriores (LE1.11). }\end{array}$ & $\begin{array}{c}\text { - Ler pequenos textos narrativos (LE1.8.1); } \\
\text { - Interpretar as intenções e as emoções } \\
\text { das personagens de uma história } \\
\text { (LE1.11.2). }\end{array}$ \\
\hline & $2 .^{\circ}$ ano & \begin{tabular}{|c} 
- Ler textos diversos \\
(LE2.8); \\
- Organizar a \\
informação de um texto \\
lido (LE2.10).
\end{tabular} & $\begin{array}{c}\text { - Ler pequenos textos narrativos (LE2.8.1); } \\
\text { - Identificar o tema ou referir o assunto do } \\
\text { texto (LE2.10.3). }\end{array}$ \\
\hline & $3 .^{\circ}$ ano & $\begin{array}{c}\text { - Ler textos diversos } \\
\text { (LE3.6); } \\
\text { - Organizar os } \\
\text { conhecimentos do texto } \\
\text { (LE3.8); } \\
\text { - Monitorizar a } \\
\text { compreensão (LE3.10); } \\
\text { - Elaborar e aprofundar } \\
\text { ideias e conhecimentos } \\
\text { (LE3.11). }\end{array}$ & $\begin{array}{c}\text { - Ler pequenos textos narrativos (LE3.6.1); } \\
\text { - Identificar o tema ou o assunto do } \\
\text { texto, assim como os eventuais subtemas } \\
\text { (LE3.8.2); } \\
\text { - Referir, em poucas palavras, o essencial } \\
\text { do texto (LE3.8.4); } \\
\text { - Sublinhar as palavras desconhecidas, } \\
\text { inferir o significado a partir de dados } \\
\text { contextuais e confirmá-lo no dicionário } \\
\text { (LE3.10.1); } \\
\text { - Exprimir e maneira apropriada uma } \\
\text { opinião crítica a respeito de um texto } \\
\text { e compará-lo com outros já lidos ou } \\
\text { conhecidos (LE3.11.3). }\end{array}$ \\
\hline & $4 .^{\circ}$ ano & \begin{tabular}{|c|} 
- Ler textos diversos \\
(LE4.7); \\
- Monitorizar a \\
compreensão (LE4.11).
\end{tabular} & $\begin{array}{l}\text { - Ler textos narrativos (LE4.7.1); } \\
\text { - Identificar segmentos de texto que não } \\
\text { compreendeu (LE4.11.1). }\end{array}$ \\
\hline
\end{tabular}


Da análise da Tabela 4 inferimos que os estudantes privilegiaram a leitura de pequenos textos narrativos, destacando-se, no que respeita ao $3 .^{\circ}$ ano de escolaridade, a maior atenção dada à operacionalização de descritores de desempenho que possibilitam a monitorização da compreensão (podendo contribuir para a valorização de alguns objetivos relativos à Educação Literária, nesse nível de ensino).

A seleção dos descritores de desempenho por parte dos grupos revela ainda, à semelhança do sucedido relativamente à Educação Literária, a desvalorização concedida ao estabelecimento de inferências nas suas planificações, o que nos parece merecer uma reflexão atenta, no respeitante à formação destes estudantes.

A Tabela 5 elucida-nos sobre os objetivos e respetivos descritores de desempenho contemplados nas planificações dos grupos no âmbito do domínio da Leitura e Escrita (2. ${ }^{\circ}$ Ciclo do Ensino Básico):

Tabela 5 - Objetivos e descritores da Leitura e Escrita - 2. ${ }^{\circ}$ Ciclo do Ensino Básico

\begin{tabular}{|c|c|c|c|}
\hline Domínio & $\begin{array}{c}\text { Ano de } \\
\text { escolaridade }\end{array}$ & Objetivos & Descritores de desempenho \\
\hline \multirow{2}{*}{$\begin{array}{c}\text { Leitura e } \\
\text { Escrita }\end{array}$} & $5 .^{\circ}$ ano & $\begin{array}{l}\text { - Compreender o } \\
\text { sentido dos textos } \\
\text { (LE5.7); } \\
\text { - Organizar a } \\
\text { informação contida } \\
\text { no texto (LE5.9). }\end{array}$ & $\begin{array}{l}\text { - Detetar e distinguir entre informação } \\
\text { essencial e acessória, tomando notas } \\
\text { (LE5.7.3); } \\
\text { - Indicar a intenção do autor, justificando a } \\
\text { partir de elementos do texto (LE5.9.3). }\end{array}$ \\
\hline & 6. ${ }^{\circ}$ ano & $\begin{array}{l}\text { - Compreender o } \\
\text { sentido dos textos } \\
\text { (LE6.7); } \\
\text { - Organizar a } \\
\text { informação contida } \\
\text { no texto (LE6.9). }\end{array}$ & $\begin{array}{l}\text { - Realizar, ao longo da leitura de textos longos, } \\
\text { sínteses parciais (de parágrafos ou secções), } \\
\text { formular questões intermédias e enunciar } \\
\text { expectativas e direções possíveis (LE6.7.1); } \\
\text { - Relacionar a estrutura do texto com a } \\
\text { intenção e o conteúdo do mesmo (LE6.7.3) }\end{array}$ \\
\hline
\end{tabular}

Da análise da Tabela 5 depreendemos que os objetivos mais valorizados pelos estudantes foram semelhantes relativamente ao $5 .^{\circ}$ e ao $6 .^{\circ}$ ano de escolaridade, diferindo, apenas, os descritores de desempenho selecionados.

Importa notar a ausência de descritores de desempenho cuja operacionalização pode contribuir para o incremento do desenvolvimento da compreensão na leitura, com particular ênfase na compreensão crítica, como por exemplo: «Fazer inferências a partir da informação prévia ou contida no texto» (LE.6.8) e «Avaliar criticamente textos» (LE6.10).

Para compreendermos, de forma mais aprofundada, o modo como os estudantes encaravam o cruzamento dos objetivos traçados no âmbito do domínio da Educação Literária com o ensino do desenvolvimento da compreensão na leitura (domínio da Leitura e Escrita), analisámos as estratégias do leitor incluídas nas planificações $\left(1 .^{\circ} \mathrm{e}\right.$ 
2. ${ }^{\circ}$ Ciclos do Ensino Básico), de acordo com as diferentes fases do ato de leitura (Sá, 2014), como mostra a Tabela 6:

Tabela 6 - Estratégias do leitor: $1 .^{\circ}$ e $2 .^{\circ}$ Ciclos do Ensino Básico

\begin{tabular}{|c|c|c|c|c|c|}
\hline Categorias & Subcategorias & Ocorrências & $\%$ & Total & $\%$ \\
\hline \multirow{3}{*}{ Pré-leitura } & Ativação de conhecimentos prévios & 1 & $1,8 \%$ & \multirow{3}{*}{14} & \multirow{3}{*}{$25 \%$} \\
\hline & Elaboração de previsões & 3 & $5,4 \%$ & & \\
\hline & $\begin{array}{l}\text { Formulação de questões sobre o texto } \\
\text { (pelos alunos/pelas alunas) }\end{array}$ & 10 & $17,9 \%$ & & \\
\hline \multirow{4}{*}{ Leitura } & Leitura atenta do texto & 3 & $5,4 \%$ & \multirow{4}{*}{19} & \multirow{4}{*}{$34 \%$} \\
\hline & Sublinhar elementos do texto & 12 & $21,4 \%$ & & \\
\hline & $\begin{array}{c}\text { Confronto das previsões feitas com a } \\
\text { informação recolhida }\end{array}$ & 3 & $5,4 \%$ & & \\
\hline & Construção de inferências & 1 & $1,8 \%$ & & \\
\hline \multirow{5}{*}{ Pós-leitura } & Releitura do texto & 1 & $1,8 \%$ & \multirow{5}{*}{23} & \multirow{5}{*}{$41 \%$} \\
\hline & Identificação das ideias principais do texto & 12 & $21,4 \%$ & & \\
\hline & Consulta do dicionário & 4 & $7,1 \%$ & & \\
\hline & Identificação do tipo/género textual & 5 & $8,9 \%$ & & \\
\hline & $\begin{array}{l}\text { Recurso ao contexto para encontrar o } \\
\text { significado das palavras/expressões que } \\
\text { não foram compreendidas }\end{array}$ & 1 & $1,8 \%$ & & \\
\hline Total & & 56 & $100 \%$ & 56 & $100 \%$ \\
\hline
\end{tabular}

Fonte: Elaboração própria

Da análise da Tabela 6, podemos inferir que os estudantes concederam maior relevo à fase da Pós-leitura (23 ocorrências, correspondendo a 41\%), seguindo-se a Leitura (19 ocorrências, correspondendo a 34\%). A Pré-leitura (14 ocorrências, correspondendo a $25 \%$ ) recebeu menos destaque nas planificações dos estudantes.

No que respeita à Pré-leitura, a "Ativação de conhecimentos prévios» foi muito depreciada pelos estudantes (1 ocorrência, correspondendo a 1,8\%), apontando para o desconhecimento do seu papel fundamental para o desenvolvimento da compreensão na leitura, aspeto crescentemente sublinhado na literatura de especialidade (Kostons \& Werf, 2015; Tarchi, 2015)

Relativamente à leitura, a atenção dos estudantes focou-se em «Sublinhar elementos do texto» (12 ocorrências, correspondendo a 21,4\%), sendo muito desvalorizada a «Construção de inferências» (1 ocorrência, correspondendo a 1,8\%). Embora sublinhar elementos do texto seja relevante para o fomento da compreensão na leitura, importa que tal atividade seja complementada por outras, sendo a construção de inferências consensualmente reconhecida como muito relevante no âmbito da formação do leitor (Duke, Pearson, Strachan \& Billman, 2011; Sim-Sim, 2007). 
No que se refere à Pós-leitura ganhou relevo, nas planificações dos estudantes, a «Identificação das ideias principais do texto» (12 ocorrências, correspondendo a $21,4 \%$ ), sendo muito depreciada a «Releitura do texto» (1 ocorrência, correspondendo a 1,8\%). Tal desvalorização merece, também, reflexão. Face aos desafios atuais impostos por práticas de leitura de caráter crescentemente fragmentário (alimentado, por vezes, em contexto escolar, pela sucessiva opção por excertos de textos, com supressões, em detrimento da leitura integral da obra), a releitura, realizada de forma cuidada e atenta parece, muitas vezes, ser relegada para segundo plano, comprometendo a aliança entre prazer na leitura e a motivação para a mesma.

\section{Considerações finais}

O estudo efetuado possibilitou-nos caracterizar as representações da Educação Literária que emergiram das planificações que os estudantes realizaram, contemplando os domínios da Educação Literária e da Leitura e Escrita.

Depreendemos que a Educação Literária seria valorizada pelos estudantes em contexto de sala de aula, nomeadamente no que respeita a «Ler e ouvir ler obras de literatura para a infância» (1. ${ }^{\circ}$ Ciclo do Ensino Básico) e a "Ler e interpretar textos literários» (2. ${ }^{\circ}$ Ciclo do Ensino Básico). O cruzamento do domínio da Educação Literária com o domínio da Leitura e Escrita permitiu-nos compreender que os estudantes concediam também algum relevo à monitorização da compreensão, incluída nas suas planificações.

No entanto, embora tenham valorizado a Educação Literária, procurando conciliar os seus objetivos com o desenvolvimento de estratégias didáticas para o ensino explícito da compreensão na leitura, os estudantes depreciaram muito o estabelecimento de inferências e a ativação de conhecimentos prévios. Atribuíram, igualmente, pouco relevo à motivação para a leitura, o que aponta para a necessidade de conceder mais atenção ao seu perfil de leitor, no entendimento de que a sua própria formação se refletirá, possivelmente, nas suas práticas educativas futuras.

\section{Notas}

1 Entendida, no presente contexto, de acordo com a formulação do Programa e Metas Curriculares de Português (Buescu, Morais, Rocha \& Magalhães, 2015).

2 A seleção realizada pelos grupos foi precedida de uma escolha individual, por parte dos estudantes, no âmbito do seu trabalho autónomo. Posteriormente, cada grupo teve oportunidade de, consensualmente, escolher a obra/o texto que pretendia utilizar, no âmbito da planificação proposta.

3 Utilizamos como referencial teórico Sá (2014).

4 É facultado, entre parêntesis, nas tabelas 2 a 5, em primeiro lugar, o domínio selecionado e, posteriormente, a numeração seguida no Programa e Metas Curriculares de Português (Buescu et al., 2015), no que respeita ao objetivo e ao descritor de desempenho mencionados. Foi adotado o mesmo procedimento no corpo do texto. 


\section{Referências Bibliográficas}

Azevedo, F. \& Balça, Â. (2016) (Coord.). Leitura e educação literária. Lisboa: PACTOR.

Baleiro, R. (2011). A literacia da leitura literária no ensino universitário (Tese de doutoramento, não publicada). Lisboa: Universidade Nova de Lisboa. [Disponível em http://hdl.handle.net/10362/7227, consultado em março 2015].

Bernardes, J. \& Mateus, R. (2013). Literatura e ensino do Português. Lisboa: Fundação Francisco Manuel dos Santos.

Bona, J. \& Silva, N. M. A. (2009). Cultura e práticas escolares: um olhar a partir das representações sociais. Revista Espaço Pedagógico, 16 (2), 7-19.

Buescu, H., Morais, J., Rocha, M. R. \& Magalhães, V. M. (2015). Programa e metas curriculares de Português do ensino básico. Lisboa: Direção-Geral da Educação]. [Disponível em http://www. dge.mec.pt/sites/default/files/Basico/Metas/Portugues/pmcpeb_julho_2015.pdf, consultado em outubro 2015].

Ceia, C. (2011). Revisão do perfil do professor de literatura. In J. A. Silva, J. C. Martins e M. Gonçalves (Orgs.). Pensar a liter@tura no século XXI (pp. 279-286). Braga: Universidade Católica Portuguesa.

Duke, N. K., Pearson, P. D., Strachan, S. L. \& Billman, A. K. (2011). Essential elements of fostering and teaching reading comprehension. In S. J. Samuels \& A. E. Farstrup (Eds.), What research has to say about reading instruction ( $4^{\text {th }}$ ed.) (pp. 51-93) Newark, DE: International Reading Association.

EACEA/Eurydice (2012). O ensino da leitura na Europa: contextos, políticas e práticas. Lisboa, Editorial do Ministério da Educação e Ciência (Trabalho original publicado em 2011).

Fernandes, R. S. G. \& Maia, R. F. (2013). Comportamento leitor de universitários: um estudo com alunos de administração e computação. Anais do SILEL, 3, (1). Uberlândia: EDUFU. [Disponível em http:// www.academia.edu/6694796/Comportamento_Leitor_de_Universit\%C3\%A1rios_Um_Estudo_ com_Alunos_de_Administra\%C3\%A7\%C3\%A30_e_Computa\%C3\%A7\%C3\%A3, consultado em setembro 2015].

Granado, C. (2014). Teachers as readers: a study of the reading habits of future teachers/ El docente como lector: estudio de los hábitos lectores de futuros maestros. Cultura y Educación/Culture and Education, 26 (1), 44-70. doi: 10.1080/11356405.2014.908666

Juchum, M. (2014). A escrita na universidade: uma reflexão com base no que os alunos dizem em seus textos. Horizontes de Linguística Aplicada, 13 (1), 107-129. [Disponível em http://periodicos.unb.br/ index.php/horizontesla/article/viewFile/11597/10864, consultado em setembro, 2015].

Kostons, D. \& Werf, G. (2015). The effects of activating prior topic and metacognitive knowledge on text comprehension scores. British Journal of Educational Psychology. 85, 3, 264-275. doi: 10.1111/ bjep.12069

Mangen, A. (2016). The digitization of literary reading: contributions from empirical research. Orbis Litterarum, 71 (3), 240-262.

Martos Nuñez, E. \& Campos Fernández-Figares, M. (2013). Diccionario de nuevas formas de lectura y escritura. Madrid: Editorial: RIUL- Santillana. 
Melão, D. (2016). Representações sobre a leitura e sua influência em práticas educativas. Um estudo no $1{ }^{\circ}$ ciclo de Bolonha. (Tese de doutoramento; não publicada). Aveiro: Universidade de Aveiro.

Menezes, D. A. \& Coelho, F. A. (2016). (Des)caminhos da educação literaria: do ensino básico ao superior. Diadorim, 18 (1), 77-91.

Moscovici, S. (1976). La psychanalyse, son image et son publique, 2ème édition. Paris: PUF. (Trabalho original publicado em 1961).

Nogueira, C. (2011). Os textos da tradição oral portuguesa no $3 .^{\circ}$ ciclo do ensino básico e no ensino secundário. Revista Lusófona de Educação, 17, 91-101. [Disponível em http://revistas.ulusofona.pt/ index.php/rleducacao/article/view/2367, consultado em janeiro 2016].

Oliveira, K. L. (2011). Considerações acerca da compreensão em leitura no ensino superior. Psicologia: Ciência e Profissão, 31 (4), 690-701. [Disponível em http://www.scielo.br/scielo.php?script=sci_artt ext\&pid=\$141498932011000400003, consultado em setembro 2015].

Owusu-Acheaw, M. \& Larson, A. G. (2014). Reading habits among students and its effect on academic performance: a study of students of Koforidua Polytechnic. Library Philosophy and Practice (e-journal), 1-22. [Disponível em: http://digitalcommons.unl.edu/libphilprac/1130, consultado em julho 2015]

Parlette, M. \& Howard, V. (2010). Personal growth, habits and understanding: pleasure reading among first-year university students. Evidence based library and information practice, 5 (4), 5369. [Disponível em http://wigan-ojs.library.ualberta.ca/index.php/EBLIP/article/viewFile/8630/7522, consultado em julho 2015].

Sá, C. M. (2014). Estratégias do leitor. Aveiro: Universidade de Aveiro/Departamento de Didática e Tecnologia Educativa [documento policopiado].

Sim-Sim, I. (2007). O ensino da leitura: a compreensão de textos. Lisboa: Direção Geral de Inovação e Desenvolvimento Curricular.

Tarchi, C. (2015). Fostering reading comprehension of expository texts through the activation of readers' prior knowledge and inference-making skills. International Journal of Educational Research, 72, 8088.

Yubero, S., Larrañaga, E. \& Pires, N. (2014). Estudo sobre os hábitos de leitura dos estudantes portugueses do ensino superior. Castelo Branco: Edições IPCB. 
Dulce Melão

Escola Superior de Educação de Viseu Instituto Politécnico de Viseu, Portugal

E-mail: dulcemelao@esev.ipv.pt

Correspondência

Dulce Melão

Escola Superior de Educação de Viseu Departamento de Ciências da Linguagem

Rua Maximiano Aragão 3504-501 Viseu

Data de submissão: Janeiro 2016

Data de avaliação: Março 2016

Data de publicação: Setembro 2017 